\section{International Scientific Journal Theoretical \& Applied Science}

p-ISSN: 2308-4944 (print) $\quad$ e-ISSN: 2409-0085 (online)

Year: 2017 Issue: $06 \quad$ Volume: 50

Published: $30.06 .2017 \quad$ http://T-Science.org
Lyudmila Famil Ismailova

Senior lecturer of the Department "Organization of business and management", Sumgait State University, Azerbaijan Republic nauka-xxi@mail.ru

SECTION 19. Management. Marketing. Public administration.

\title{
THE IMPORTANT ASPECTS OF ENTREPRENEURSHIP IN THE DEVELOPMENT OF THE NON-OIL SECTOR OF AZERBAIJAN'S ECONOMY IN THE CONTEXT OF IMPLEMENTATION OF STRATEGIC ROAD MAPS
}

\begin{abstract}
The important aspects of entrepreneurship in the development of the non-oil sector of the economy in the context of the implementation of strategic road maps in Azerbaijan are examined in the article. The main directions and priorities of the development of the non-oil sector of the country's economy, the essence of the state policy of Azerbaijan in the sphere of entrepreneurship of the non-oil sector are analyzed. The activity of the structure of the market economy in the country, its effectiveness, the main indicators of entrepreneurs in small and medium businesses, joint ventures, foreign companies in Azerbaijan are considered. The problems are revealed and the importance of intensifying the development of entrepreneurship in the non-oil sectors of the economy under the current conditions is substantiated. The rationality of entrepreneurship development to create new jobs, increase employment and solve social and economic problems is studied.

A number of recommendations on important aspects and problems of entrepreneurship in the development of the non-oil sector of the economy in the context of the implementation of strategic road maps in Azerbaijan are compiled and given at the end of the article.

Key words: Azerbaijan, important aspects of entrepreneurship, development of the non-oil sector, strategic road maps, intensification of business development, development of small and medium-sized businesses, increasing activity of private entrepreneurs.

Language: Russian

Citation: Ismailova LF (2017) THE IMPORTANT ASPECTS OF ENTREPRENEURSHIP IN THE DEVELOPMENT OF THE NON-OIL SECTOR OF AZERBAIJAN'S ECONOMY IN THE CONTEXT OF IMPLEMENTATION OF STRATEGIC ROAD MAPS. ISJ Theoretical \& Applied Science, 06 (50): 152-157.

Soi: http://s-o-i.org/1.1/TAS-06-50-21 Doi: crossef https://dx.doi.org/10.15863/TAS.2017.06.50.21

\section{ВАЖНЫЕ АСПЕКТЫ ПРЕДПРИНИМАТЕЛЬСТВА В РАЗВИТИИ НЕНЕФТЯНОГО СЕКТОРА ЭКОНОМИКИ АЗЕРБАЙДЖАНА В УСЛОВИЯХ РЕАЛИЗАЦИИ СТРАТЕГИЧЕСКИХ ДОРОЖНЫХ КАРТ}

Аннотация: В статье исследованы важные аспекты предпринимательства в развитии ненефтяного сектора экономики в условиях реализации стратегических дорожных карт в Азербайджане. Анализированы основные направления и приоритеты развития ненефтяного сектора экономики страны, сущность государственной политики Азербайджана в сфере предпринимательства ненефтяного сектора. Рассмотрена деятельность структуры рыночной экономики в стране, её эффективность, основные показатели работы предпринимателей в субъектах малого и среднего бизнеса, в совместных предприятиях, иностранных компаниях в Азербайджане. Раскрыты проблемы и обоснована важность интенсификации развития предпринимательства в ненефтяных секторах экономики в нынешних условиях. Изучены рациональность развития предпринимательства по созданию новых рабочих мест, повыщению занятости и в решении социально-экономических проблем.

В конце статьи обобщены и дан ряд рекомендаџий по важным аспектам и проблемам предпринимательства в развитии ненефтяного сектора экономики в условиях реализации стратегических дорожных карт в Азербайджане.
\end{abstract}


Ключевые слова: Азербайджан, важные аспекты предпринимательства, развитие ненефтяного сектора, стратегические дорожные карты, интенсификация развития предпринимательства, развитие малого и среднего предпринимательства, повышение активности частных предпринимателей.

\section{Introduction}

Вопросы и проблемы развития экономики страны считаются одними из главных направлений формирования и реализации государственной политики в современных условиях. Однако проблемы развития национальной экономики, эффективное использование её ресурсного потенциала, развитие производства, совершенствование процесса воспроизводства во все времена считались актуальными и находились в центре внимания правителей, правительств, государств и Т.Д.

\section{Materials and Methods}

В период интенсификации развития капиталистических подходов, развитие воспроизводства и повышение рациональности ресурсов развития экономики нуждались в особом внимании, которые считались очень важными с точки зрения обеспечения взаимосвязи и взаимодействия ресурсов с вложенным капиталом[1]. Кроме того, в период развития процессов индустриализации, особый акцент был сделан на оптимальность выбора развития промышленных предприятий и в целом промышленности с учётом их эффективности и перспективного развития. Важным считалось обеспечение развития промышленности с учётом специфики национальной экономики и близкого расположения к тем местам, где больше всего сконцентрированы природные ресурсы и прочий ресурсный потенциал, способствующий более эффективной организации деятельности промышленности в целом[2]. Отметим, что данный подход и в современный период также рассматривается, как один из главных критерий в процессах развития промышленности с учётом рационального использования его ресурсного потенциала. Если рассмотреть спецификацию и прочие принципы развития промышленности, особенно её ненефтяной сектор экономики, то можно заметить, что основные крупные промышленные предприятия находятся вблизи её ресурсных источников. Например, Сумгайытский промышленный центр, где сконцентрированы основные предприятия и комплексы ненефтяных секторов экономики - предприятия химических, нефтехимических, металлургических. Основным источником сырья здесь служат побочные продукции и полуфабрикаты, перерабатываемые из нефти и газа. Или развитие современного металлургического комплекса вблизи другого крупного промышленного центра Азербайджана - в Гяндже связано с близостью железных руд в
Дашкесенском районе. В целом, для эффективного развития ненефтяных секторов экономики в Азербайджане характерен аналогичный принцип, однако требуется комплексный подход и более адекватные механизмы формирования конкурентоспособности ненефтяного сектора экономики страны в условиях роста глобальных угроз, углубления рыночных отношений и деформации мирохозяйственных процессов. В связи с продолжением влияния негативных последствий финансового кризиса в мире и плюс к этому с падением цен на нефть, которая является главным источником валютных доходов и финансовых ресурсов Азербайджана требуется повышение рационального использования имеющегося ресурсного потенциала страны и в том числе финансового ресурса. Вопросы обеспечения рациональности формирования и движения финансовых ресурсов, их использование должны основываться на более продуктивном и надёжном механизме национальной экономики[3]. В период замедления притоков финансовых ресурсов становится проблематичным реализация проектов инфраструктурного характера или создание производственных мощностей разных секторов национальной экономики, в которых в нынешних условиях особо наблюдается в процесс развития ненефтяных секторов экономики Азербайджана. Дело в том, что за последние десятилетия со стороны государства вложены огромные финансовых ресурсы в развитие инфраструктуры во всех областях, в том числе в экономику и социальные сферы. Государство активно помогает развитию предпринимательства, выделяет льготные кредиты, безвозмездно отдаёт субсидии, компенсирует расходы на минеральные удобрения, сельскохозяйственную технику, то есть создаёт удобства и благоприятную среду для интенсификации процессов роста уровня предпринимательской деятельности и бизнессреды в стране. Подобные мероприятия способствуют постепенному росту объёма и влияния ненефтяных секторов экономики страны в структуре национальной экономики, тем самым создают реальную почву для минимизации зависимости экономики страны от нефтяных факторов. Пожалуй, эта задача и проблема являются самыми важными по диверсификации структуры национальной экономики, повышению её конкурентоспособности и укреплению в международном разделении труда, обеспечению экономической активности регионов страны и 
использованию производственных сил, улучшению жизненного состояния населения страны. В случае реализации этих факторов и задач Азербайджан получит исторический шанс по укреплению своего места в среде конкурентоспособных стран мира и сможет модернизировать, и в то же время совершенствовать свои модели экономического развития в контексте глобальных изменений и глобальных угроз. В процессах развития отдельных секторов экономики страны, одной из важных проблем является привлечение иностранных инвестиций и крупного капитала в ту или иную отрасль с сопровождением применения передового опыта управления[4]. Государство должно заботиться не только о стимулировании иностранных инвестиций, но и должно обеспечить эффективные практичные механизмы по их реализации и развитию отдельных секторов экономики страны адекватных её ресурсному потенциалу[5]. Азербайджан, после приобретения независимости, в первую очередь, особо воспользовался преимущественным фактором национальной экономики для выхода на мировые рынки и сразу взялся за интенсификацию развития главного сектора - добывающей отрасли нефти и газа. Начиная с середины 1990-х годов, был заложен фундамент для развития нефтяного сектора и должны отметить, что это оправдало себя. Уже, в начале XXI века, Азербайджан занимал не только лидирующую позицию среди государств региона, но одновременно выступал инициатором и финансовым источником реализации крупных энергетических проектов, которые способствовали активному выходу на мировые рынки и укреплению международного имиджа страны. Как было отмечено ранее, в связи с падением цен на нефть оказалось, что одной нефтью и газом обеспечить конкурентоспособность национальной экономики невозможно, и образовалась острая необходимость интенсификации развития ненефтяного сектора экономики Азербайджана. В числе механизмов и приоритетных направлений развития экономической модели в Азербайджане в современных условиях особое значение отводится развитию предпринимательства в ненефтяных секторах экономики страны. Аналогичный подход стал одним из приоритетных и стратегических направлений для развития экономики страны в нынешних условиях. Профессор Р.Гулиев отмечает, что помимо развития нефтяной промышленности в стране был принят курс на диверсификацию экономики - развитию ненефтяного сектора[6, с. 34]. Более того, этот курс является стратегическим и развитием ненефтяного сектора в экономической политики Азербайджана, прежде всего, осуществляется в первую очередь за счёт интенсификации и расширения предпринимательской деятельности в стране. Профессор Ш.Садыгов подчёркивает, что за прошедшие 14 лет для развития предпринимательской деятельности в аграрном секторе экономики большое внимание уделялось строительству новых и наращиванию действующих объектов мелиорации и ирригации, так за этот период их бюджетное финансирование увеличилось в 8,7 раза... Вопрос ресурсной поддержки предпринимательства всегда оставался приоритетным направлением финансово-кредитной политики. Сейчас страна обладает современной, адекватной своей экономике, устойчивой бюджетной и гибкорегулируемой банковской системами. Это позволяет обеспечить макроэкономическую стабильность, задействовать потенциал стимулирования и финансирования предпринимательского сектора, активизировав, тем самым, его участие в развитие экономики страны[7, с. 97]. Кроме того, развитие ненефтяного сектора и одновременно активизация предпринимательской деятельности способствует совершенствованию и развитию эффективности модели экономического развития страны. Во многом это объясняется традиционной популярностью предпринимательства и склонности азербайджанцев. Предпринимательство не является новшеством и феноменом для суверенного Азербайджана. В принципе, азербайджанцы возвращаются в профессиональную сферу, исторически присущую менталитету и образу мышления нации. Азербайджан испокон веков - страна богатых предпринимательских и купеческих традиций, поэтому предпринимательство можно считать потенциалом нашего национального умения и способности. Сегодня же созданы необходимые правовая база для претворения в жизнь свободной предпринимательской деятельности. Так, принят ряд законов, создающих условия для формирования предпринимательства. В числе этих пакетов документов - законы «О предпринимательской деятельности», «Об акционерных обществах», «О земельной реформе», «Об антимонопольной деятельности», «О товарной бирже», «О ценных бумагах» и т.д[8]. Более того, для развития предпринимательской деятельности, особенно малого предпринимательства на два года отменены все виды внешних контрольных проверок со стороны государственных органов с целью уменьшения вмешательства в их деятельность. Неслучайно, сегодня Азербайджанская экономика вступает в новый 
этап развития... Большая половина ВВП формируется ненефтяным сектором, и в ближайшее время зависимость от нефти исчезнет совсем[9, с. 100].

Отметим, что развитие малого и среднего предпринимательства в Азербайджанской Республике особо сказывается на развитии регионов, на снижении бедности, повышении занятости и экономической активности населения страны. В последние пятнадцать лет обеспечение развития малого и среднего предпринимательства в Азербайджанской Республике являлось приоритетом осуществляемым со стороны государственной социально-экономической политики[10, с. 44]. Социальные аспекты предпринимательской деятельности приводят в конечном счёте к росту благосостояния народа и всестороннему развитию личности каждого человека[11, с. 122]. Результаты деятельности рыночной экономики и работы малого предпринимательства в Азербайджана показывают, что развитие предпринимательства и её интенсификации государственной поддержки способствуют экономической активности и проявлению предпринимательской предприимчивости граждан страны, в целом усилению занятости и участия малых предпринимателей, физических лиц - частных предпринимателей, которые вносят немалые вклады в развитие экономики страны и расширение перечня продукции, которые способствуют росту общего национального продукта. В Таблице 1 отражены показатели деятельности структуры рыночной экономики в Азербайджанской Республике.

Таблица 1

Показатели деятельности структуры рыночной экономики в Азербайджанской Республике.

\begin{tabular}{|c|c|c|c|c|c|c|c|}
\hline$\Pi / \mathrm{H}$ & Показатели & 2005 & 2010 & 2012 & 2013 & 2014 & 2015 \\
\hline 1 & $\begin{array}{l}\text { Число функционирующих малых } \\
\text { предприятий, единица }\end{array}$ & 11982 & 14532 & 13658 & 14461 & 14981 & 17847 \\
\hline 2 & $\begin{array}{lcc}\text { Число } & \text { функционирующих } \\
\text { иностранных } & \text { и } & \text { совместных } \\
\text { предприятий, единица } & \end{array}$ & 796 & 1091 & 1083 & 1193 & 1270 & 1235 \\
\hline 3 & $\begin{array}{l}\text { Списочное число работающих в } \\
\text { малых предприятиях, человек }\end{array}$ & 73447 & 93205 & 95503 & 108976 & 115035 & 87626 \\
\hline 4 & $\begin{array}{l}\text { Списочное число работающих в } \\
\text { иностранных и } \\
\text { предприятиях, человек }\end{array}$ & 58413 & 55936 & 76651 & 84946 & 91753 & 93002 \\
\hline 5 & $\begin{array}{l}\text { Объём выпускаемой продукции в } \\
\text { малых предприятиях, млн. манат }\end{array}$ & 657,5 & 1776,9 & 2404,4 & 3139,8 & 2547,2 & 959,0 \\
\hline 6 & $\begin{array}{l}\text { Объём выпускаемой продукции в } \\
\text { иностранных и } \\
\text { предприятиях, млн. манат }\end{array}$ & 7081,4 & 24011,9 & 29439,5 & 30130,0 & 27590,1 & 23423,1 \\
\hline
\end{tabular}

Примечание: Таблица 1 подготовлена автором на основе материалов Государственного Статистического Комитета Азербайджанской Республики. http://www.azstat.gov.az

Анализ Таблицы 1 показывает, что число функционирующих малых предприятий постоянно растёт и в 2015 году составило 17,8 тысяч единиц, в которых работают 87,6 тысяч человек, а в 1235 иностранных и совместных предприятиях трудятся свыше 93 тысяч человек. Показатели субъектов малого предпринимательства в Азербайджанской Республике даны в Таблице 2. 


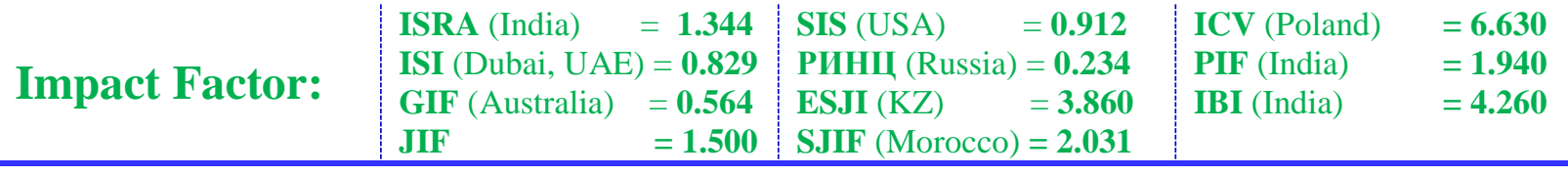

Таблица 2

Показатели субъектов малого предпринимательства в Азербайджанской Республике.

\begin{tabular}{|c|c|c|c|c|c|c|}
\hline & Показатели & 2005 & 2010 & 2013 & 2014 & 2015 \\
\hline \multirow[t]{2}{*}{1} & $\begin{array}{l}\text { Число субъектов малых предпринимателей, } \\
\text { всего: из них }\end{array}$ & 177722 & 207120 & $\begin{array}{l}16527 \\
7\end{array}$ & 186898 & $\begin{array}{l}18327 \\
1\end{array}$ \\
\hline & $\begin{array}{l}\text { физические лица - частные предприниматели: } \\
\text { в том числе: }\end{array}$ & 166558 & 192588 & $\begin{array}{l}15081 \\
6\end{array}$ & 171917 & $\begin{array}{l}16542 \\
4\end{array}$ \\
\hline \multirow[t]{2}{*}{2} & $\begin{array}{l}\text { сельское хозяйство, лесное } \\
\text { рыболовство }\end{array}$ & 4000 & 3953 & 3997 & 3410 & 3193 \\
\hline & физические лица - частные предприниматели & 2681 & 2618 & 2334 & 1624 & 1534 \\
\hline \multirow[t]{2}{*}{3} & промышленность & 3824 & 4616 & 6173 & 6418 & 4551 \\
\hline & физические лица - частные предприниматели & 1824 & 2643 & 3369 & 4697 & 3310 \\
\hline \multirow[t]{2}{*}{4} & строительство & 1723 & 1534 & 1936 & 2335 & 2340 \\
\hline & физические лица - частные предприниматели & 248 & 560 & 924 & 1007 & 895 \\
\hline \multirow[t]{2}{*}{5} & торговля; ремонт транспортных средств & 124268 & 133803 & 87446 & 91690 & 96731 \\
\hline & физические лица - частные предприниматели & 120086 & 127501 & 81041 & 85338 & 89950 \\
\hline \multirow[t]{2}{*}{6} & транспорт и складское хозяйство & 18029 & 22148 & 27862 & 28178 & 28443 \\
\hline & физические лица - частные предприниматели & 17792 & 21908 & 27576 & 27877 & 28131 \\
\hline \multirow[t]{2}{*}{7} & размещение туристов и общественное питание & 9166 & 13455 & 9406 & 12863 & 14162 \\
\hline & физические лица - частные предприниматели & 8951 & 13127 & 9157 & 12511 & 13638 \\
\hline
\end{tabular}

Примечание: Таблица 2 подготовлена автором на основе материалов Государственного Статистического Комитета Азербайджанской Республики. http://www.azstat.gov.az.

На основе Таблицы 2 можно отметить, что число субъектов малых предпринимателей тоже отличается динамичным ростом за 2005-2014 годы, хотя в 2015 году наблюдалось снижение, связанное с негативными последствиями падения цен на нефть на мировом рынке, которые пока имеет существенное влияние на экономические процессы в стране. Частные предприниматели больше всего сконцентрированы в торговле, транспорте, общественном питании и туристическом секторе.

Следует подчеркнуть, что в ближайшей перспективе рассматривается осуществление стратегических задач в развитии экономики страны в основном за счёт расширения ненефтяного сектора и активизации предпринимательской деятельности, чтобы преобразовать существующие экономические механизмы в контексте требований глобальных вызовов и негативных последствий мировых экономических процессов. Президент Азербайджана, Ильхам Алиев, в статье «Экономические приоритеты Азербайджана на 2017 год», размещённой на официальном сайте Давосского экономического форума отмечает, что: "Наряду с достигнутыми реальными

ISPC Technology and Education,

Philadelphia, USA успехами, мы столкнулись и с вызовами. Процессы глобального экономического кризиса отразились и на экономике Азербайджана, сократились доходы, за минувший год национальная валюта подешевела в 10,1 процента... Я уверен, что в 2017 год станет годом развития экономики Азербайджана. Мы продолжим осуществление эффективных экономических реформ”[12]. А для реализации стратегических целей и задач определены важные направления развития экономики страны, в том числе «Стратегические дорожные карты относительно производству потребительских товаров на уровне малого и среднего предпринимательства в Азербайджанской Республике» в рамках стратегических дорожных карт, утверждённой Указом Президента Азербайджанской Республики от 6 декабря 2016 года[13].

\section{Conclusion}

Таким образом, в условиях роста глобальных угроз ожидается пристальное внимание руководства страны на развитие предпринимательства, особенно малого и среднего предпринимательства в разных секторах 
экономики с повышением их эффективности, продуктивности, которые будут существенно влиять на интенсификацию расширения предпринимательской деятельности и в целом на развитие ненефтяного сектора экономики Азербайджана в условиях реализации стратегических дорожных карт и т.д.

\section{References:}

1. Alfred Marshall (1891) Principles of Economics, 1890-1891.

2. Alfred Weber (1909) Über den Standort der Industrie. Bd. 1: Reine Theorie des Standorts. 1909.

3. Gerard T, Darragh F, Stephen M (2014) A Needs and Resources Assessment of Fiscal Ecualisation in the Irish Local Government System// The Economic and Social Review, by Thomson Reuters, Web of Science Impact Factor (2014): 0,522. Vol. 46, No. 3, Autumn, 2015, p. 459-484.

4. (1196) World Conservation Strategy. Living Resource Conservation for Sustainable Development. International Union for Conservation of Nature and Natural Resources. 1196 Gland, Switzerland.-76 p.

5. Sachs D Jeffre (2017) Economics of sustainable development. Available: Http://www.inosmi.ru. (Accessed: 10.06.2017).

6. Guliyev R (2015) Modern economic models and Azerbaijan // EKONOMIKA, 6 (171), 2015.- p. 31-35.

7. Sadygov SM (2014) Priority development of the non-oil sector in the economic policy of Azerbaijan // Investitsii: Practice ta dosvid, No. 15 / 2014.-p. 94-99.

8. Mamedli I (2017) A successful model of an independent economy. Available: Http://www.inosmi.ru. (Accessed: 10.06.2017).
9. Huseynov SR (2014) Non-profit sector as a competitive factor of Azerbaijan's economic development // Journal of Russian Entrepreneurship, No. 13 (259), 2014.- p. 93101.

10. Hajiyeva ST (2016) The Current State and Prospects for the Development of Small and Medium-Sized Enterprises in the Republic of Azerbaijan // Innovation: Practice and Information, No. 14 / 2016.-P. 44-48.

11. Babayev KM (2013) Social Aspects of Entrepreneurial Activity in the Conditions of Market Relations // Economics and Management, 2 (99), 2013.- p. 119-122.

12. (2017) The official website of the Davos Economic Forum featured an article by Ilham Aliyev entitled "Azerbaijan's Economic Priorities for 2017". Official website of the President of the Republic of Azerbaijan. Available: $\quad$ Http://www.ru.president.az. (Accessed: 10.06.2017).

13. (2016) Decree of the President of the Republic of Azerbaijan on the approval of strategic road maps for the national economy and the main sectors of the economy. December 06, 2016 Baku. Official website of the President of the Republic of Azerbaijan. Official web site Available: $\quad$ http://www.ru.president.az. (Accessed: 10.06.2017). 